Keywords: SCIX, RMF, Rotary Filter

Retention: Permanent

\title{
Rotary Filter Fines Testing for Small Column Ion Exchange
}

D.T. Herman

August 2011

Savannah River National Laboratory

Savannah River Nuclear Solutions, LLC

Aiken, SC 29808

Prepared for the U.S. Department of Energy under contract number DE-AC09-08SR22470.

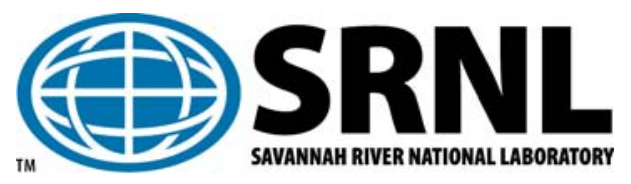




\section{DISCLAIMER}

This work was prepared under an agreement with and funded by the U.S. Government. Neither the U.S. Government or its employees, nor any of its contractors, subcontractors or their employees, makes any express or implied:

1. warranty or assumes any legal liability for the accuracy, completeness, or for the use or results of such use of any information, product, or process disclosed; or

2. representation that such use or results of such use would not infringe privately owned rights; or

3. endorsement or recommendation of any specifically identified commercial product, process, or service.

Any views and opinions of authors expressed in this work do not necessarily state or reflect those of the United States Government, or its contractors, or subcontractors.

\section{Printed in the United States of America \\ Prepared for U.S. Department of Energy}




\section{REVIEWS AND APPROVALS}

AUTHOR

D.T. Herman

Date

Advanced Characterization and Processing Group

Technical Review

DESIGN CHECK (per E7 2.60)

L.N. Oji

Date

Advanced Characterization and Processing Group

APPROVAL

F.M. Pennebaker, Manager

Date

Advanced Characterization and Processing Group

S.L. Marra, Manager

Date

Environmental \& Chemical Process Technology Research Programs

T.H. Huff, Manager

Date

SCIX Engineering 


\section{ACKNOWLEDGEMENTS}

The author expresses his appreciation to Luay Albakri of SpinTek Filtration for coordinating and conducting the tests described in this report. The author would also like to express his appreciation to Bill Greene and Jason Gilmour of SpinTek Filtration for their support and input throughout testing. Thanks also to David DiPrete of Savannah River National Laboratory (SRNL) for the titanium analysis methodology. 


\section{EXECUTIVE SUMMARY}

SRNL was requested to quantify the amount of "fines passage" through the 0.5 micron membranes currently used for the rotary microfilter (RMF). Testing was also completed to determine if there is any additional benefit to utilizing a 0.1 micron filter to reduce the amount of fines that could pass through the filter. Quantifying of the amount of fines that passed through the two sets of membranes that were tested was accomplished by analyzing the filtrate by Inductively Coupled Plasma Atomic Emission Spectrometry (ICP-AES) for titanium. Even with preparations to isolate the titanium, all samples returned results of less than the instrument's detection limit of $0.184 \mathrm{mg} / \mathrm{L}$. Test results show that the 0.5 micron filters produced a significantly higher flux while showing a negligible difference in filtrate clarity measured by turbidity. 


\section{TABLE OF CONTENTS}

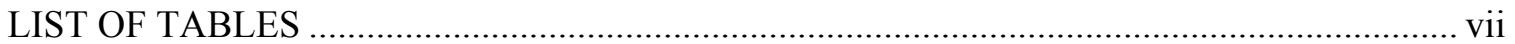

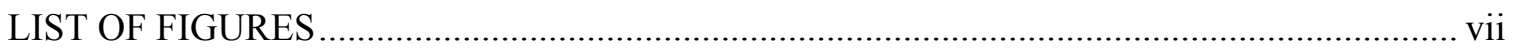

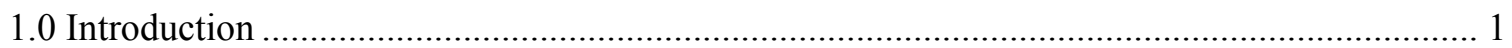

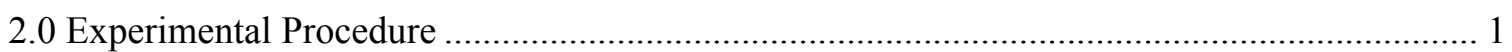

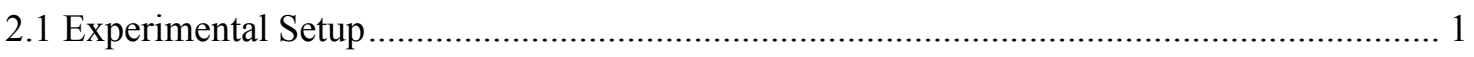

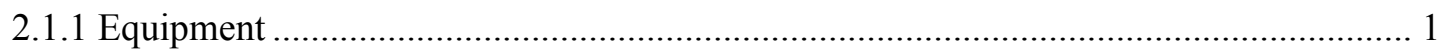

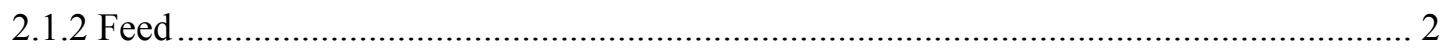

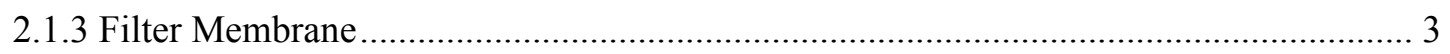

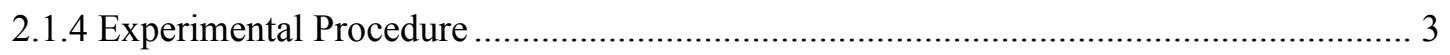

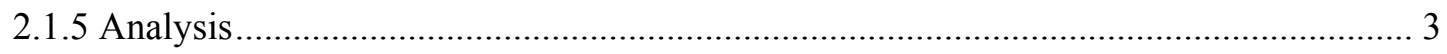

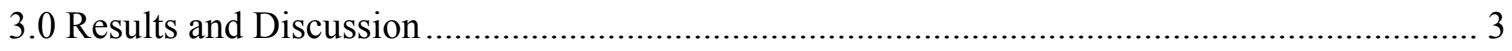

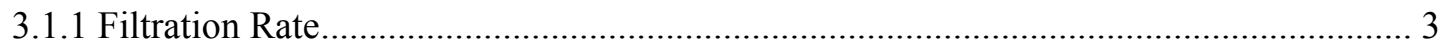

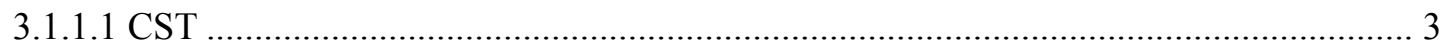

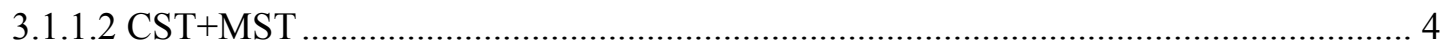

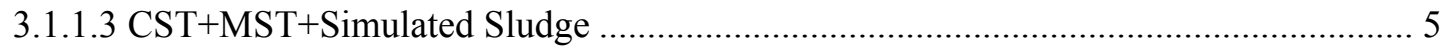

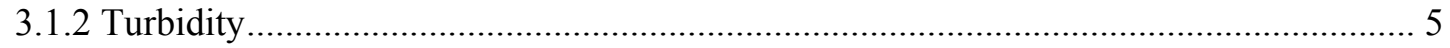

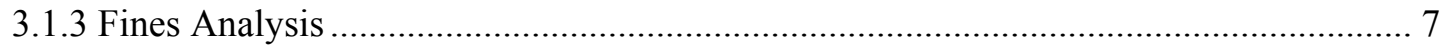

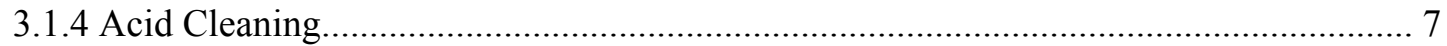

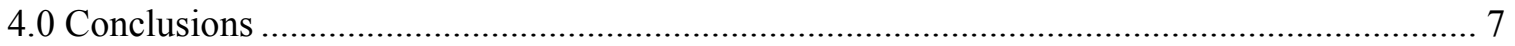

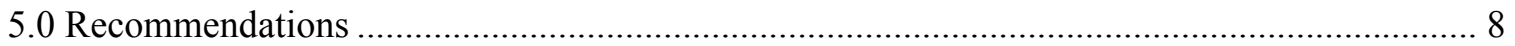

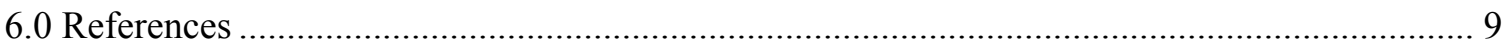

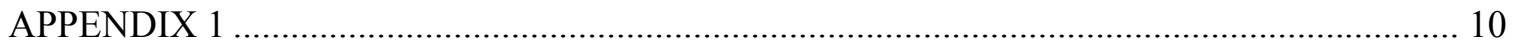

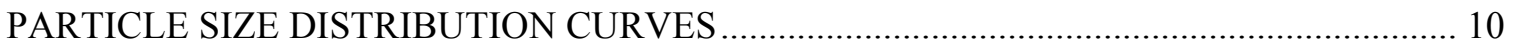




\section{LIST OF TABLES}

Table 2-1. . Simulated Supernate Composition. 3

\section{LIST OF FIGURES}

Figure 2-1. Three Disk Rotary Filter System ……................................................................. 2

Figure 3-1. Permeate Flow Rate with $6.8 \mathrm{~g} / \mathrm{L}$ of CST in Simulated Salt Solution......................... 4

Figure 3-2. Permeate Flow Rate with CST and MST in Simulated Salt Solution........................ 4

Figure 3-3. Permeate Flow Rate with CST, MST, and Sludge in Simulated Salt Solution............ 5

Figure 3-4. Filtrate Turbidity Measurements for all Tests as a Function of Test Time.................. 6

Figure 3-5. Feed and Filtrate Samples from CST Feed Using 0.1 Micron Filter Disks ................. 7 


\section{LIST OF ABBREVIATIONS}

$\begin{array}{ll}\text { CST } & \text { Crystalline Silicotitanate } \\ \text { DWPF } & \text { Defense Waste Processing Facility } \\ \text { gpm } & \text { Gallons Per Minute } \\ \text { HLW } & \text { High Level Waste } \\ \text { ICP-AES } & \text { Inductively Coupled Plasma Atomic Emission Spectrometry } \\ \text { M } & \text { Molar } \\ \text { MST } & \text { Monosodium Titanate } \\ \text { NTU } & \text { Nephelometric Turbidity Unit } \\ \text { psi } & \text { Pound per Square Inch } \\ \text { RMF } & \text { Rotary Microfilter } \\ \text { SB6 } & \text { Sludge Batch 6 } \\ \text { SCIX } & \text { Small Column Ion Exchange } \\ \text { SRNL } & \text { Savannah River National Laboratory } \\ \text { SRS } & \text { Savannah River Site }\end{array}$




\subsection{Introduction}

The first targeted deployment of the RMF is with the Small Column Ion Exchange (SCIX) at the Savannah River Site (SRS). SCIX uses crystalline silicotitanate (CST) to sorb cesium to decontaminate a clarified salt solution. The passage of fine particles through the filter membranes in sufficient quantities has the potential to impact the downstream facilities. To determine the amount of fines passage, a contract was established with SpinTek Filtration to operate a 3-disk pilot scale unit with prototypic filter disk and various feeds and two different filter disk membranes. SpinTek evaluated a set of the baseline 0.5 micron filter disks as well as a set of 0.1 micron filter disks to determine the amount of fine particles that would pass the membrane and to determine the flux each set produced. The membrane on both disk sets is manufactured by the Pall Corporation (PMM 050). Each set of disks was run with three feed combinations: prototypically ground CST, CST plus monosodium titanate (MST), and CST, MST, plus Sludge Batch 6 (SB6) simulant. Throughout the testing, samples of the filtrate were collected, measured for turbidity, and sent back to SRNL for analysis to quantify the amount of fines that passed through the membrane. It should be noted that even though ground CST was tested, it will be transferred to the Defense Waste Processing Facility (DWPF) feed tank and is not expected to require filtration.

\subsection{Experimental Procedure}

\subsection{Experimental Setup}

\subsubsection{Equipment}

Three-disk pilot scale RMF was used in testing with prototypic filter disks. The three disk unit was selected to minimize the amount of feed material required for testing. A photo of the unit is shown as Figure 2-1. 


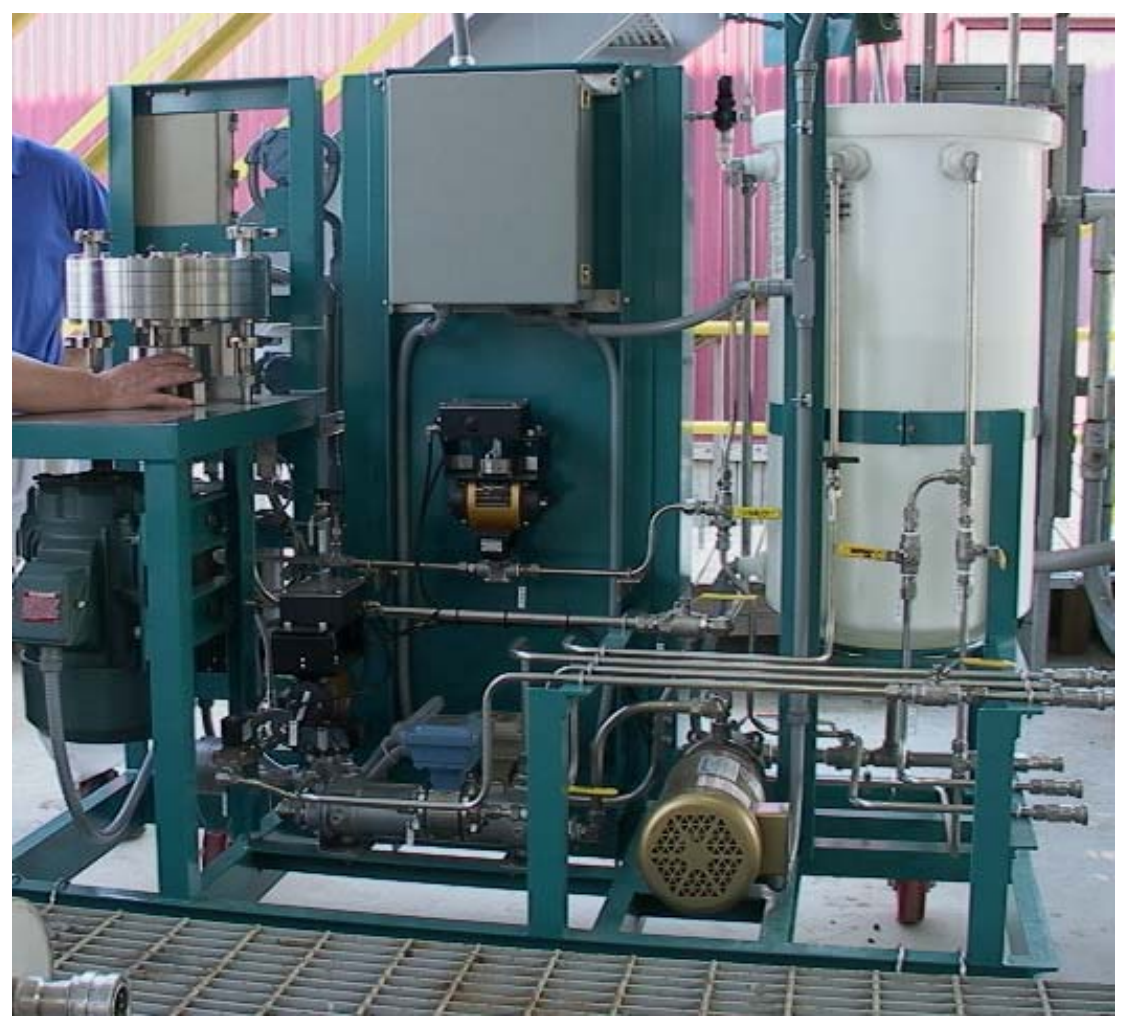

Figure 2-1. Three Disk Rotary Filter System

The system utilizes three full sized disks oriented horizontally. The filter chamber is the stainless steel structure in the upper left hand corner of the photo.

\subsubsection{Feed}

Three feeds were run through the filter: ground CST, ground CST with MST, and ground CST with MST and simulated sludge. Feed concentrations were based on standard MST concentration with the CST and simulated sludge concentrations which are consistent with previous testing for the SCIX program ${ }^{1}$ of:

\section{$0.4 \mathrm{~g} / \mathrm{L}$ of MST \\ 17:1 CST to MST ratio \\ 2:3 MST to Sludge ratio}

The CST used in the fines testing was ground CST from the previous vendor testing (Hockmeyer). ${ }^{2}$ The MST used for the testing was obtained from batches currently used in the Actinide Removal Process. The simulated sludge used in the testing was the SB6 Batch $2^{3}$ previously used in RMF testing. Particle size distributions are given as Attachment 1.

The base salt solution is a nominal 5.6 molar (M) sodium salt solution consisting of components as shown in Table 2-1. 
Table 2-1. Simulated Supernate Composition

\begin{tabular}{|c|c|}
\hline Component & Concentration (M) \\
\hline Free $\mathrm{OH}^{-}$ & $1.33 \mathrm{E}+00$ \\
\hline $\mathrm{NaNO}_{3}$ & $2.60 \mathrm{E}+00$ \\
\hline $\mathrm{NaAl}(\mathrm{OH})_{4}$ & $4.29 \mathrm{E}-01$ \\
\hline $\mathrm{NaNO}_{2}$ & $1.34 \mathrm{E}-01$ \\
\hline $\mathrm{Na}_{2} \mathrm{SO}_{4}$ & $5.21 \mathrm{E}-01$ \\
\hline $\mathrm{Na}_{2} \mathrm{CO}_{3}$ & $2.60 \mathrm{E}-02$ \\
\hline Total Na & $\mathbf{5 . 6}$ \\
\hline
\end{tabular}

\subsubsection{Filter Membrane}

Each feed was run using a set of three prototypic filter disks with a baseline 0.5 micron Pall membrane. In addition, a set of three prototypic size filter disks with a Pall 0.1 micron filter membrane (PMM 020) was tested with each feed. The filter disks were purchased from SpinTek for this testing.

\subsubsection{Experimental Procedure}

The filter was run at the historical running condition ${ }^{4}$ with a nominal pressure drop across the membrane of 40 pounds per square inch (psi). The filtrate outlet pressure was atmospheric with no filtrate backpressure. Feed flow rate ranged between 5.75 and 6.10 gallons per minute (gpm) for all tests. Feed temperature was approximately $95^{\circ} \mathrm{F}$. The individual tests were conducted for a minimum of 100 hours with the longest test lasting almost 137 hours.

Three tests were run using the following feeds:

CST in simulated supernate at $6.8 \mathrm{~g} / \mathrm{L}$

CST + MST in simulated supernate with $6.8 \mathrm{~g} / \mathrm{L} \mathrm{CST} \mathrm{and} 0.4 \mathrm{~g} / \mathrm{L} \mathrm{MST}$

$\mathrm{CST}+\mathrm{MST}+$ Sludge with $6.8 \mathrm{~g} / \mathrm{L} \mathrm{CST}, 0.4 \mathrm{~g} / \mathrm{L} \mathrm{MST}$, and $0.6 \mathrm{~g} / \mathrm{L}$ Sludge

During testing, data was recorded manually and the system was monitored remotely with manual data collection during off-shift hours.

\subsubsection{Analysis}

During the testing, daily filtrate samples were pulled and the turbidity was measured. In addition, samples were analyzed by ICP-AES in order to quantify for titanium, which is a major component of both CST and MST.

\subsection{Results and Discussion}

\subsubsection{Filtration Rate}

\subsubsection{CST}

Filtering CST only is not expected to occur during deployment. The CST-only test was conducted to determine the penetration of CST fines through the filter. The filtration rate for the 0.5 and 0.1 micron filter membranes is shown as Figure 3-1. The 0.5 micron membrane produced approximately $0.02 \mathrm{gpm}$ more flow per square foot than the 0.1 micron media after the flux had 
decayed over the 100 hours of testing. This is almost $50 \%$ greater flux at the end of the test. See turbidity result discussions in Section 3.1.2.

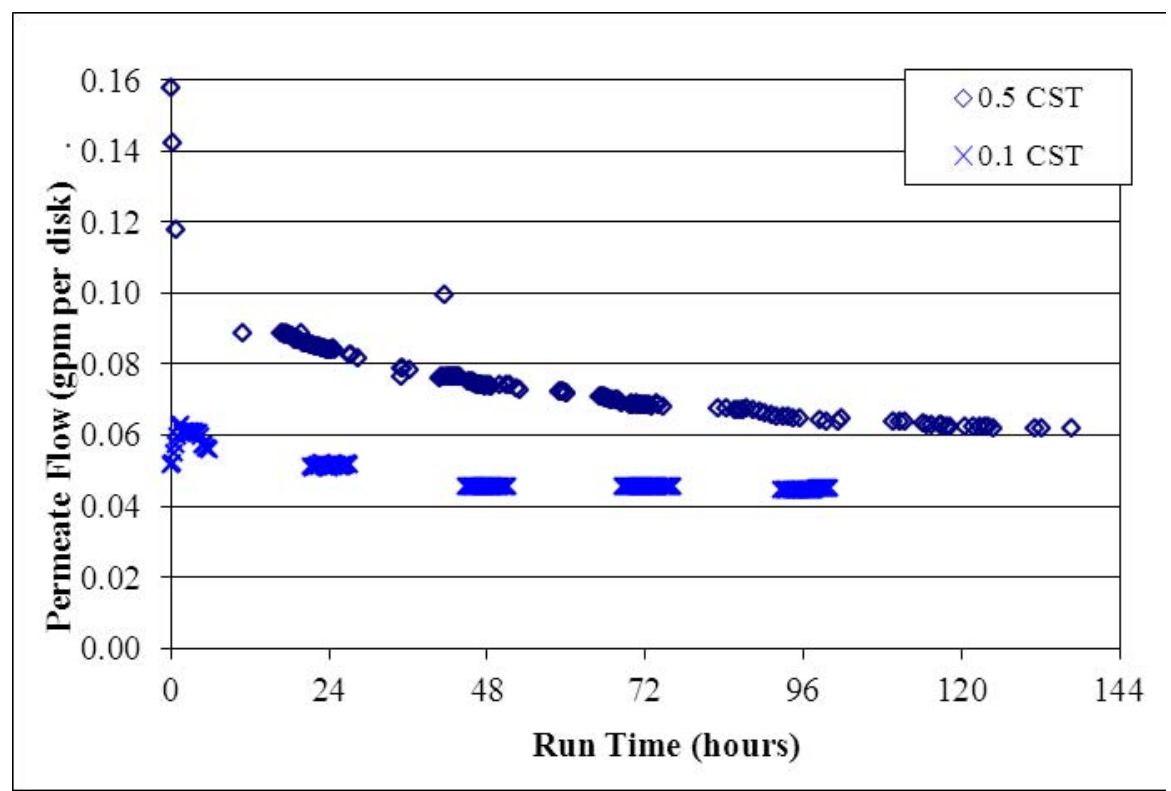

Figure 3-1. Permeate Flow Rate with $6.8 \mathrm{~g} / \mathrm{L}$ of CST in Simulated Salt Solution

\subsubsection{CST+MST}

Filtration rate results for the feed containing CST + MST are shown in Figure 3-2. The addition of MST improved the rate of filtration. The 0.5 micron membrane again demonstrated a higher filtration rate with the same off-set of approximately $0.02 \mathrm{gpm}$ per square feet of media after the flux had decayed over the 100 hours of testing. This is almost $30 \%$ greater flux at the end of the test.

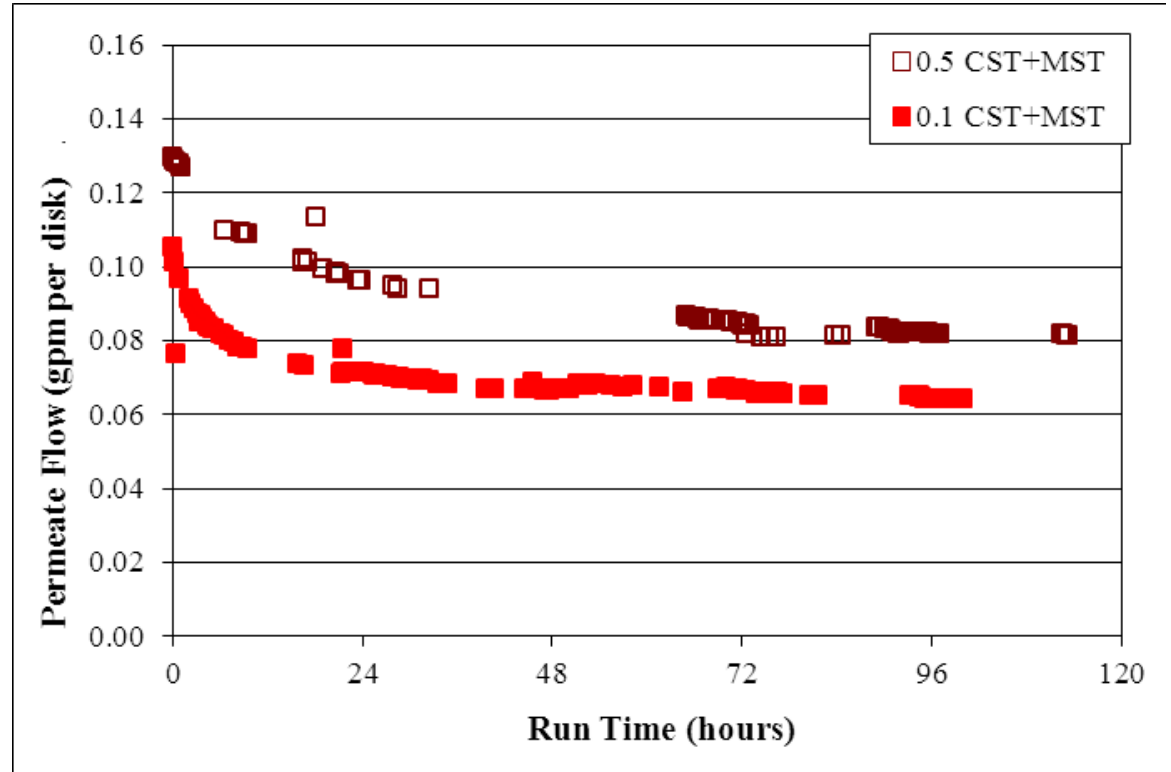

Figure 3-2. Permeate Flow Rate with CST and MST in Simulated Salt Solution 


\subsubsection{CST+MST+Simulated Sludge}

Filtration rate results for the feed containing CST, MST, and the simulated sludge are shown in Figure 3-3. Again, the 0.5 micron media produced a higher filtration rate per square foot of media. However, with the addition of sludge, the offset was only $0.01 \mathrm{gpm}$ per square foot instead of the $0.2 \mathrm{gpm}$ per square foot observed in the other feeds. This was approximately $12 \%$ greater flux for the 0.5 micron filter media when compared with the 0.1 micron filter media.

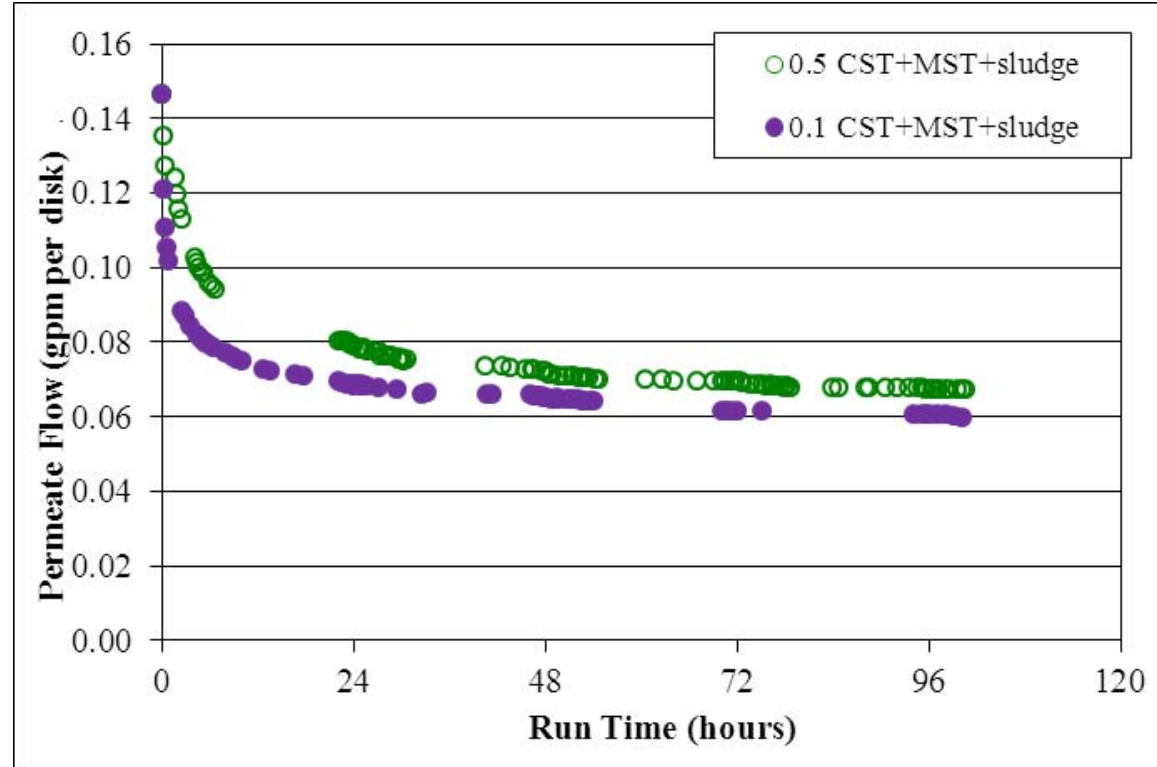

Figure 3-3. Permeate Flow Rate with CST, MST, and Sludge in Simulated Salt Solution

The addition of a small amount of sludge reduced filtration from 0.082 to 0.067 gpm per disk for the 0.5 membrane and 0.064 to 0.060 gpm per disk for the 0.1 micron membrane when compared with the previous feed of CST + MST without sludge. The addition of the sludge narrowed the difference in performance for the two membranes.

\subsubsection{Turbidity}

The results of the filtrate turbidity measurements are shown in Figure 3-4. In general, the turbidity decreased as the test proceeded indicating that the filter cake would prevent the fines from passing through the membranes. There was one exception; during the CST-only test with the 0.5 micron filters, the initial turbidity was the highest (consistent with all of the other tests) but the second sample had the lowest turbidity. The subsequent samples all showed a slight increase in turbidity. Values for turbidity were very low $(\leq 0.5$ Nephelometric Turbidity Unit $[\mathrm{NTU}])$.

Other results worth noting are that the CST-only tests with the 0.1 micron filters had the highest initial turbidity. It also maintained the highest turbidity for the daily samples compared to the other tests. This was surprising due to the tighter pore structure of the media. The tests with the next highest day-one sample measurements were both 0.5 micron filters. The day-two samples from those tests were the minimum turbidities when compared to the day- 2 samples from the 
other tests. The lowest day- 1 sample turbidity was the 0.5 micron filters with CST + MST and sludge.

In general, the samples demonstrated that the tighter pore size was no benefit to turbidity. After the filter cake formed on the membranes, it became the dominant filter controlling the amount of fines passing through the filter. Two tests had two samples pulled in the first day. The second sample pulled on the same day showed a substantial drop in turbidity in both cases. The drop was very similar to the second day samples. The timing of the samples showed that the drop in turbidity happens quickly, several hours, and does not require days.

All other samples ended up with essentially identical results after the first day of testing with all turbidities less than 1 NTU.

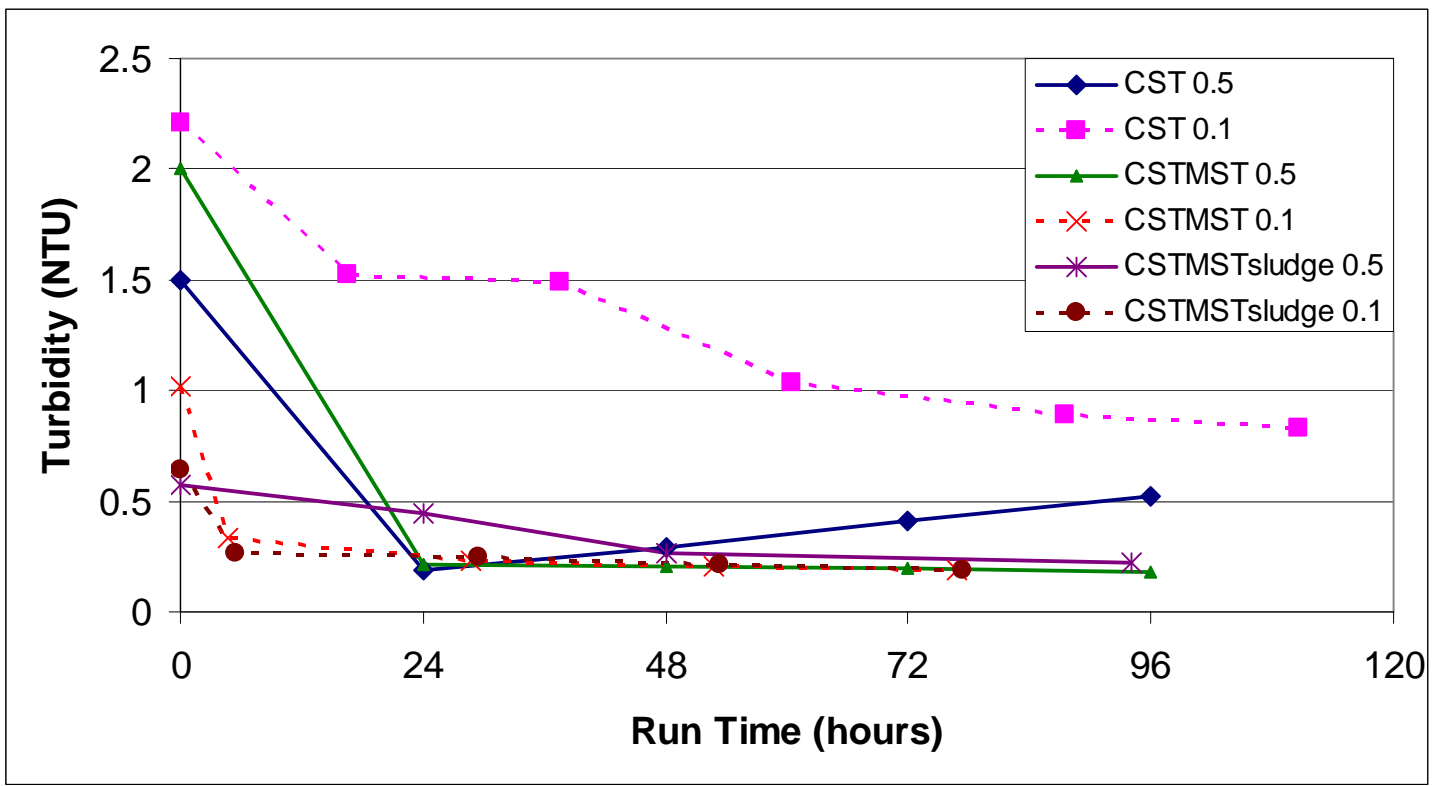

Figure 3-4. Filtrate Turbidity Measurements for all Tests as a Function of Test Time

An illustration of the feed and filtrate samples are shown in Figure 3-5. 


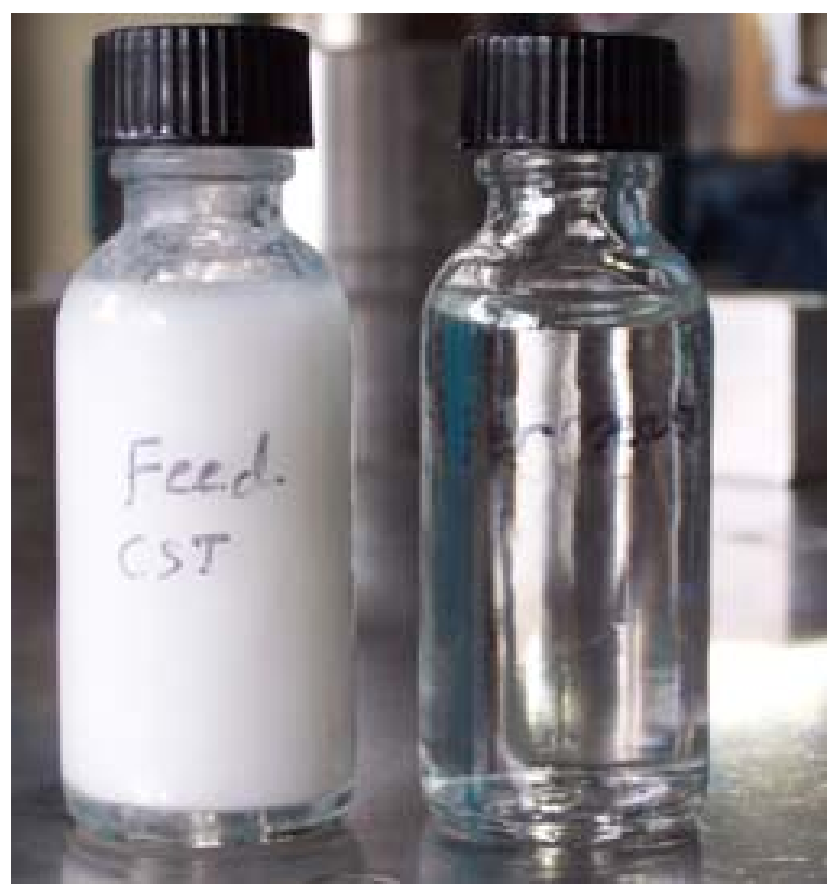

Figure 3-5. Feed and Filtrate Samples from CST Feed Using 0.1 Micron Filter Disks

\subsubsection{Fines Analysis}

Filtrate samples were submitted for titanium analysis. Aliquots were wet ashed with concentrated nitric acid. The dissolutions were brought to dryness and reconstituted in dilute nitric acid. The dissolutions were then analyzed by ICP-AES to measure the concentration of titanium, thus tracking concentrations of CST/MST still present in the filtrate. Results of the analysis of the filtrate samples for titanium were less than the detection limit of $0.184 \mathrm{mg} / \mathrm{L}$ for all samples. Therefore, the filter removed greater than $99.997 \%$ of the original CST solids from the feed solution based on the highest turbidity sample. Removal efficiency is expected to improve as turbidity decreases. Therefore, as filtration continued, the removal efficiency is expected to have increased as turbidity sample results decreased.

\subsubsection{Acid Cleaning}

Each set of filter disks was cleaned between tests. The cleaning was accomplished by soaking the disks overnight in nitric acid and rinsing with de-ionized and distilled water. After the initial test of the $6.8 \mathrm{~g} / \mathrm{L} \mathrm{CST-only} \mathrm{samples,} \mathrm{the} \mathrm{disks} \mathrm{were} \mathrm{soaked} \mathrm{overnight} \mathrm{in} 1 \mathrm{M}$ nitric acid. After these tests, the disks were soaked in $3 \mathrm{M}$ nitric acid overnight to determine if the higher acid strength would enhance cleaning of the disks. No substantial difference was noted. Cleaning was deemed successful since each following test demonstrated increased initial filtration rate.

\subsection{Conclusions}

These test results show that the 0.5 micron Pall filter provides the same filtrate clarity as the 0.1 micron Pall filter membrane while producing a significantly higher flux. Turbidity measurements were all less than $2.5 \mathrm{NTU}$ with turbidity decreasing as the filter continued to operate. Final turbidities were less than $1.0 \mathrm{NTU}$ for all samples. 
An attempt was made to quantify the amount of "fines passage" through both sets of membranes by analyzing the filtrate for titanium by ICP-AES. All samples returned results of less than the instrument detection limits of $0.184 \mathrm{mg} / \mathrm{L}$. Therefore, the filter removed greater than $99.997 \%$ of the CST in the feed. Increasing the measurement detection limits will better define the removal percentage.

In these tests, it was demonstrated that soaking the filter disks overnight in acid (from 1 to $3 \mathrm{M}$ ) was sufficient to clean the filter disks. This was confirmed by the restoration of the original flux at the start of each test feed.

\subsection{Recommendations}

SRNL recommends the usage of the current 0.5 micron Pall filter media over the 0.1 micron Pall filter media for the SCIX Program due to the higher production throughput while providing equivalent filtrate clarity. Better detection limits in the analysis for titanium may show a potential benefit to the 0.1 micron filter disks and may alter this recommendation.

It is also recommended to utilize alternative analytical techniques to improve on the detection limits for titanium in order to quantify the amount of material passing through the membrane and thus correlate it with the turbidity measurements. 


\subsection{References}

${ }^{1}$ Taylor-Pashow K. M. L., M. R. Poirier, Z. Qureshi, F. F. Fondeur, T. B. Peters, D. T. Hobbs, S. D. Fink, "Task Technical and Quality Assurance Plan for Testing to Support Modular Salt Processing Project - Monosodium Titanate Studies (U)," SRNL-RP-2010-00686, Rev. 1, October 12, 2010.

${ }^{2}$ Mohr, R. K., and I.L. Pegg, "Data Summary Report Small Column Ion Exchange (SCIX) Grinder Testing," VSL-10S2100-1, October 15, 2010.

${ }^{3}$ Herman, D.T. and M.R. Poirier, "Recipe for Simulated Sludge Batch 6-DS for Rotary Filter Testing," SRNL-TR-2009-00111, October 2009.

${ }^{4}$ Herman, D.T., “Rotary Filter 1000 Hour Test,” SRNL-STI-2010-00591, September 2010. 


\section{APPENDIX 1}

PARTICLE SIZE DISTRIBUTION CURVES

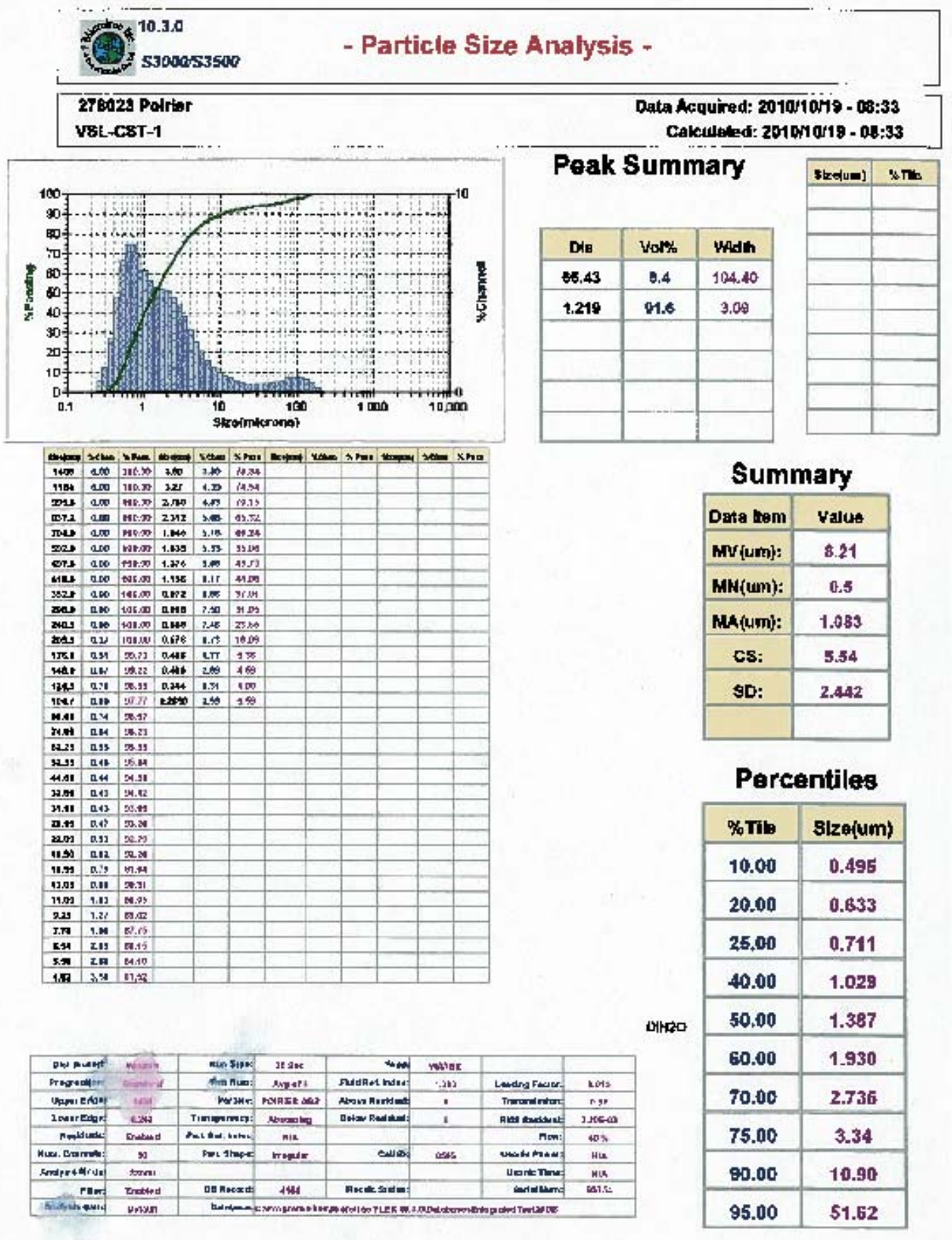




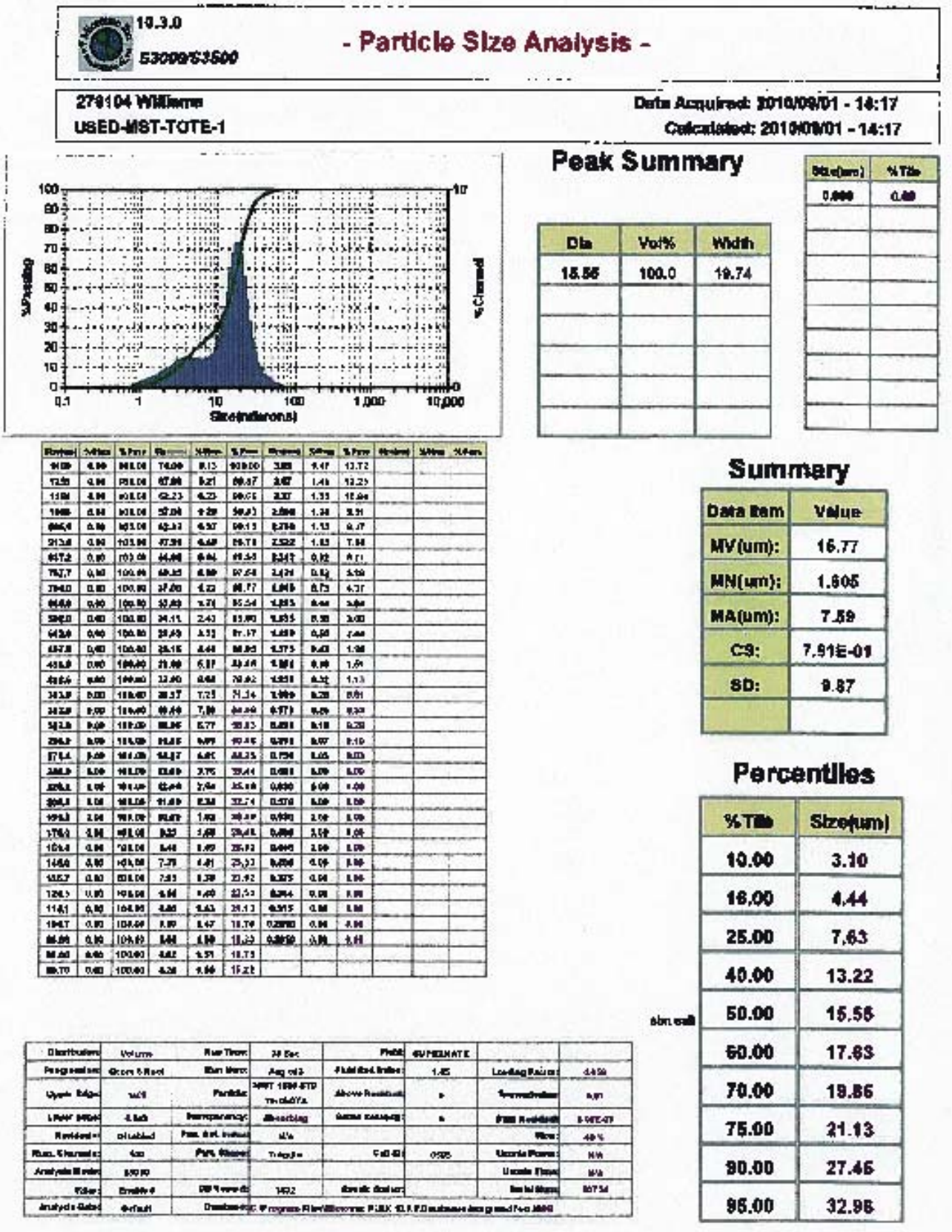


SRNL-STI-2011-00396 Revision 0
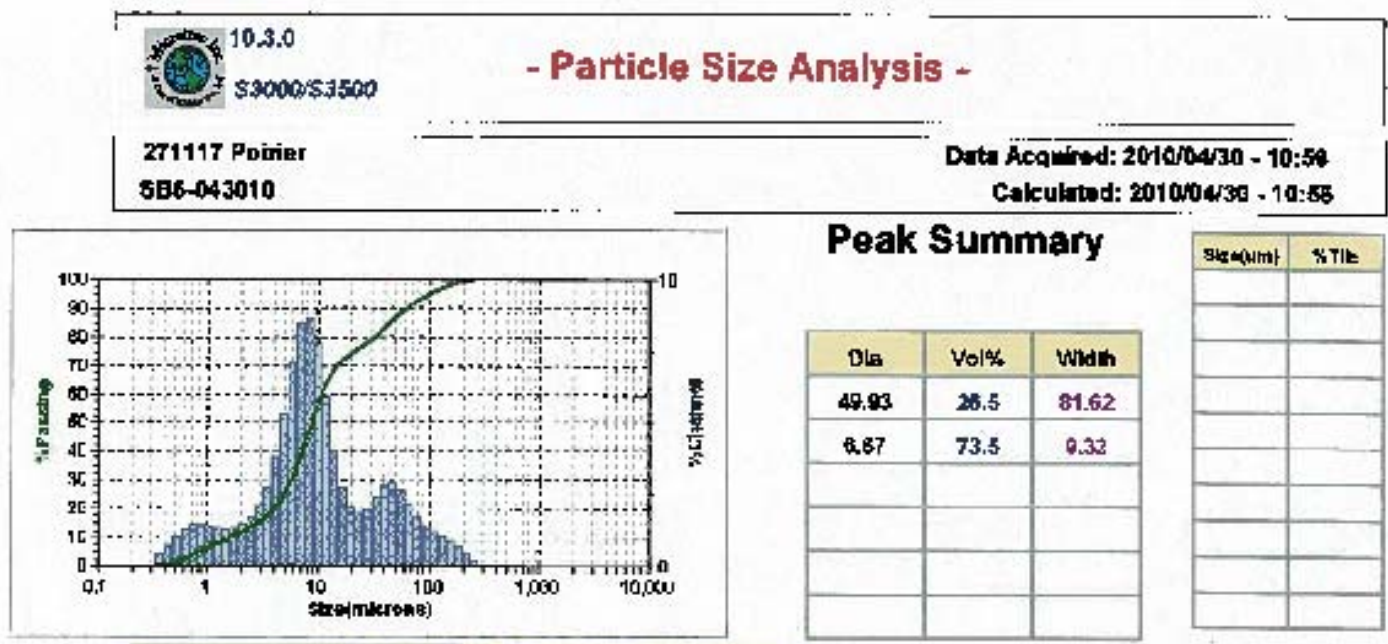

\section{Peak Summary}

\begin{tabular}{|c|c|c|}
\hline Dls & Vol\% & Whath \\
\hline 49.93 & 26.5 & 81.62 \\
\hline 2.87 & 73.5 & 0.32 \\
\hline & & \\
\hline & & \\
\hline & & \\
\hline & & \\
\hline
\end{tabular}

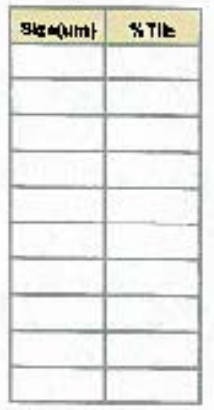

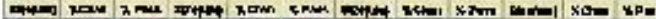

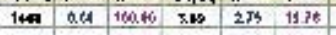

114 O.L 10010 120 211 1291

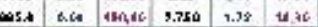

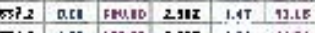

Joh hes hall Les 1.14 1171

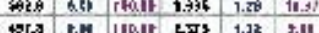

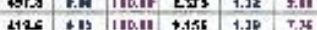

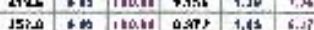

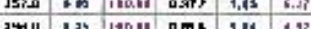

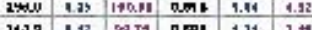

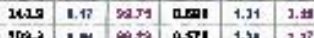

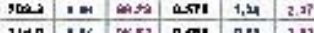

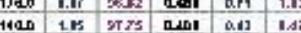

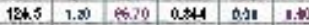

INET LAI 20.30 LIII Q.JI 1.20

IEer 173 Wh

ist ict as

1233 is rezil

\begin{tabular}{|l|l|l|l|}
1233 & 171 & 11.95
\end{tabular}

woc on mise

7i.Me 20011.17

$29.11209 \quad$ in.16

H.16 $\%$ ind

$\begin{array}{lll}2200 & 20 & 78.10\end{array}$

1156 475 7..12

19S5 2 in $76.7 \%$

19, $x, \pi$ M.is

1101

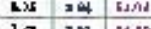

I.A 291 44AD

b.8 $62 \pi 218$

\begin{tabular}{ll|l|l|}
102 & 210 & 21.94
\end{tabular}

Summary
\begin{tabular}{|c|c|}
\hline Data lom & Vahue \\
\hline WV (um): & 22.77 \\
\hline HW\{um\}: & 0.632 \\
\hline Mh $\{$ (um): & 4.04 \\
\hline CS: & 1.484 \\
\hline SD: & 19.66 \\
\hline & \\
\hline
\end{tabular}

Percentiles
\begin{tabular}{|c|c|}
\hline$\%$ T.5 & stzi(um) \\
\hline 10.00 & 1.656 \\
\hline 20.00 & 3.94 \\
\hline 25.00 & 4.86 \\
\hline 40.00 & 7.12 \\
\hline 59.99 & 9.70 \\
\hline 50.00 & 10.78 \\
\hline 70.00 & 14.96 \\
\hline 75.00 & 20.85 \\
\hline 90.00 & 61.38 \\
\hline 95.00 & 99.10 \\
\hline
\end{tabular}

\begin{tabular}{|c|c|c|c|c|c|c|c|}
\hline Exsipition. & $10 \mathrm{ers}$ & A.... & At $2 .$. & indea & matret: & & \\
\hline Progratore & antire & mulliurs: & angars & 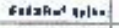 & $12 n$ & Inthen ranter: & OMA \\
\hline YYVI tove? & 1500 & Rriat & Dotant ist & Noon Mudan: & 5 & Trmentiwlen & 10 \\
\hline Lenar Dtog: & 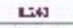 & Thmepremas: & का & 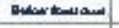 & 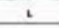 & Hon moltove: & avens \\
\hline milut & Diedens & 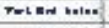 & nis & & & Rme & tas \\
\hline Hure Cumine & $n$ & restrage & iroger & $=0+100$ & whe & Verite Dana: & Hh \\
\hline 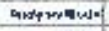 & Ean: & & & & & Werterthes & Nla \\
\hline raw: & Enthid & Do Rerest & $20 * 0$ & Bewl then- & & molemen. & $917 \% 4$ \\
\hline Anstann num & Doms & nentmers & Emongurar & 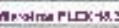 & $D=t=n$ & 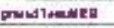 & \\
\hline
\end{tabular}
98.10 


\section{Distribution:}
A. B. Barnes, 999-W
D. A. Crowley, 773-43A
S. D. Fink, 773-A
B. J. Giddings, 786-5A
C. C. Herman, 999-W
S. L. Marra, 773-A
A. M. Murray, 773-A
F. M. Pennebaker, 773-42A
J. H. Scogin, 773-A
W. R. Wilmarth, 773-A
L. N. Oji, 773-42A
M.R. Poirier, 773-42A
D. P. DiPrete, 773-41A
M. D. Fowley, 786-5A
T. H. Huff, 773-66A
R. E. Edwards, 773-67A
D. M. Patel, 773-66A
M. A. Rios-Armstrong, 773-66A 